\title{
Genome-wide survey of Gy subunit gene family in eight Rosaceae and expression analysis of PbrGGs in pear (Pyrus bretschneideri)
}

\author{
Guodong Chen ${ }^{1 *}$, Yang $\mathrm{Li}^{1}$, Xin Qiao ${ }^{2}$, Weike Duan ${ }^{1}$, Cong Jin ${ }^{1}$, Rui Cheng ${ }^{3}$ and Jizhong Wang ${ }^{1}$
}

\begin{abstract}
Background: Heterotrimeric G-proteins, composed of $G a, G \beta$ and $G y$ subunits, are important signal transmitters, mediating the cellular response to multiple stimuli in animals and plants. The $G y$ subunit is an essential component of the G-protein, providing appropriate functional specificity to the heterotrimer complex and has been well studied in many species. However, the evolutionary history, expression pattern and functional characteristics of Gy subunits has not been explored in the Rosaceae, representing many important fruit crops.

Results: In this study, 35 Gy subunit genes were identified from the eight species belonging to the Rosaceae family. Based on the structural gene characteristics, conserved protein motifs and phylogenetic analysis of the Gy subunit genes, the genes were classified into three clades. Purifying selection was shown to play an important role in the evolution of Gy subunit genes, while a recent whole-genome duplication event was the principal force determining the expansion of the Gy subunit gene family in the subfamily Maloideae. Gy subunit genes exhibited diverse spatiotemporal expression patterns in Chinese white pear, including fruit, root, ovary and bud, and under abiotic stress conditions, the relative expression of $\mathrm{G} \gamma$ subunit genes were up-regulated or down-regulated. In addition, seven of the $\mathrm{G} \gamma$ subunit proteins in pear were located on the plasma membrane, in the cytoplasm or nucleus.
\end{abstract}

Conclusion: Overall, this study of the Gy subunit gene family in eight Rosaceae species provided useful information to better understand the evolution and expression of these genes and facilitated further exploration of their functions in these important crop plants.

Keywords: Gy subunit, Pear, Expression pattern, Abiotic stress, Subcellular localization

\section{Background}

Heterotrimeric GTP-binding proteins (G-proteins) are critical for sensing external cues and transducing the signals into cells to participate in a variety of adaptive growth and developmental responses in plants and animals [1-3]. Such responses in plants include regulation of cell growth, cell differentiation, defense, stomatal movement and ion channels, and especially the perception of

\footnotetext{
${ }^{*}$ Correspondence: chenguodong@hyit.edu.cn

${ }^{1}$ College of Life Science and Food Engineering, Huaiyin Institute

of Technology, Huai'an 223003, China

Full list of author information is available at the end of the article
}

plant hormones and sugar signals [4]. The gamma $(\mathrm{G} \gamma)$ subunit is one of the most important parts of the G-protein, binding tightly to the beta $(G \beta)$ subunit and anchoring the $G \alpha \beta \gamma$ trimer to switch the incoming signal on or off by separating from or binding to the alpha $(G \alpha)$ subunit in plants [5-7]. In plants, the first $\gamma$-subunit homolog gene was cloned and characterized from Arabidopsis in 2000 [8], following which further $\gamma$-subunit homolog genes have been identified and cloned from other plant species. In humans, a total of $12 \gamma$-subunit homolog genes have been reported, which have been shown to employ numerous combinations of their gene products to distinguish between various signals [9]. The number 
of $\gamma$-subunit homolog genes is three in Arabidopsis [2], four in tomato [10], five in rice [11] and 10 in soybean [12], and the cloning and functional analysis of $\gamma$-subunit homolog genes have also been well-studied in cucumber [7] and other plant species [13].

The structure of the animal $\mathrm{G} \gamma$ subunit has been studied in detail [14]. The $\gamma$-subunit forms a coiled-coil structure with its $\beta$-subunit partner on the $\mathrm{N}$-terminus of the $\gamma$-subunit domain, and there is a CAAX motif on the $\mathrm{C}$-terminus of the $\gamma$-subunit domain [15]. In contrast, the structure of the $\gamma$-subunit in plants shows diversity and can be divided into three different structural subtypes, namely I, II and III [16]. Type I represents the canonical form of the Gy subunit and is structurally similar to the Gy subunits found in animal cells and their fungal counterparts [17]. For example, Arabidopsis Gy1 and Gy2 belong to type I and these proteins show similar molecular weights, a conserved domain for coil interaction with $\mathrm{G} \beta$, and a conserved prenylation signal at the C-terminus [17]. Type II Gy subunits are similar to type I Gy subunits, possessing the $\mathrm{N}$-terminal $\mathrm{G} \gamma$ domain but lacking the C-terminal CAAX motif. Gy subunits, such as RGG2 in rice and SIGGB1 in tomato, belong to type II Gy subunits, although no members of the type II Gy subunits members have been found in Arabidopsis [18]. The type III $\mathrm{G \gamma}$ subunits, represented by $\mathrm{GmG \gamma} 8, \mathrm{GmG \gamma} 9$ and GmGr10 in soybean and AGG3 in Arabidopsis [12, 19, 20], have been recently discovered and are novel, plantspecific proteins that possess unique features compared with all other Gy subunits [21]. For example, these proteins are almost twice as large as the type I or type II Gy subunits, and contain a modular structure, with a Gy-like domain at its $\mathrm{N}$-terminus, followed possibly by a transmembrane domain and a long cysteine-rich C-terminal region [17].

Gy proteins are involved in the regulation of various signaling pathways affecting growth and development in plants. For example, studies have shown that AGG1 from Arabidopsis participates in auxin signaling with brassinosteroids [22]. The type II Gy protein from Brassica napus, BnGG2, also participates in hormone signaling pathways and may be involved in plant defense systems against environmental stresses [23]. The transcript abundance of the RGG1 and RGG2 genes in rice were upregulated in response to $\mathrm{NaCl}$, cold or heat stress, or to ABA exposure, which suggested that the $\mathrm{G} \gamma$ subunit played a critical role, via cross talk, in signaling pathways for promoting stress tolerance in plants $[24,25]$. In cucumber, transgenic cucumber plants $\left(\mathrm{T}_{1}\right.$ generation) constitutively overexpressing CsGG3.2 exhibited tolerance to chilling conditions and increased expression of the drought-tolerance CBF (C-repeat (CRT)/dehydrationresponsive element (DRE)) genes and their regulon [7].
In tomato, researchers showed that type II Gy subunits were involved in abscisic acid (ABA) and auxin signaling pathways during seed germination and fruit development, respectively [10]. Functional analysis of Arabidopsis type III AGG3 demonstrated its involvement in G-protein-mediated ABA signaling pathways [19], regulating organ size $[19,26]$. In soybean, the type III Gy proteins are involved during ABA-dependent inhibition of nodule formation and lateral root development in transgenic soybean hairy roots [27]. In addition, the type III Gy proteins in rice, RGG3 (GS3), RGG4 (DEP1) and RGG5 (GGC2), are associated with important quantitative trait loci (QTLs) for regulating seed length and plant architecture variables, including semi-dwarfness, panicle number and panicle erectness. These $\mathrm{G} \gamma$ proteins increased grain length individually or in combination with DEP1 $[28,29]$. Similar results were obtained in heterologous expression systems or fungi, with overexpression of AGG3 in Camelina sativa resulting in increases in yield and heavy metal stress tolerance [30]. Furthermore, the Gy subunit MGG1 from the phytopathogenic fungus Magnoporthe oryzae might act upstream of the cyclic AMP (cAMP) signaling pathway and may play critical roles in the regulation of conidiation, appressorium formation, mating and plant infection in the causal agent of rice blast, $M$. oryzae [31].

As noted previously, $\mathrm{G \gamma}$ subunit proteins play an important role in signal transduction of plant growth and development, and the members and function of the $\mathrm{G} \gamma$ subunit have been widely identified and investigated in various plants, but the members of the $G$ y subunit gene family and their functions in the Rosaceae family have not been examined in detail. In other plant families, genome analysis, facilitated by the development of high-throughput sequencing technology, has been widely used to investigate the $\mathrm{Gy}$ subunit gene family. Furthermore, pear and other Rosaceae fruit species are widely cultivated all over the word which are very popular for its nutritional and delicious. Recently, the genome of the pear (Pyrus bretschneideri) has been fully sequences and released, and genome sequences are also available for seven other Rosaceae species (apple, peach, strawberry, Japanese apricot, sweet cherry, black raspberry, and European pear). These data provide an opportunity to further analyze the Gy subunit gene family in Rosaceae species. Therefore, in this study, we used bioinformatics and molecular biology techniques to identify and characterize the $\mathrm{G} \gamma$ subunit gene members, the driving forces behind the evolution of these genes and their evolutionary history, expression patterns and subcellular localization in eight economically important fruit crop species in the Rosaceae. Our results identified a set of potential candidates $\mathrm{Gy}$ subunit genes to carry out further investigations 
of the functions and signal transduction pathways mediated by $\mathrm{G} \gamma$ subunit proteins in these important plants.

\section{Results}

\section{The Gy subunit gene family in the Rosaceae}

To identify the members of the Gy subunit gene family in the Rosaceae, we searched the entire genome sequences of each of the eight Rosaceae species, using two strategies: one approach was to use a Hidden Markov Model (HMM) file of the Gy subunit gene domain (PF00631.22) from Pfam to screen the genomes of the eight Rosaceae species, whereas the other was to use the Arabidopsis amino acid sequence of the Gy subunit as queries with which to carry out BLASTP searches against the genome databases of each of the eight Rosaceae species. Thirty-nine candidate Gy subunit genes were identified. Subsequently, redundant sequences, incomplete gene sequences and incomplete domain sequences were excluded by sequence alignment, with the completeness of the Gy subunit gene domains being analyzed using Pfam and SMART. Ultimately, a total of 35 complete and nonredundant $\mathrm{G} \gamma$ subunit genes were identified from the eight Rosaceae species, namely seven $\mathrm{G} \gamma$ subunit genes in Chinese white pear, three in strawberry, eight in apple, four in European pear, three in sweet cherry, five in peach, two in black raspberry and three in Japanese apricot (Fig. 1).

Previous studies had shown that whole-genome duplication (WGD) events play a crucial role in the expansion and evolution of plant genes [32]. In the apple genome, two rounds of WGD events have been observed, a recent WGD (Ks -0.2) and the paleoduplication event corresponding to the $\gamma$ triplication (Ks -1.6) [33, 34]; while in the pear genome, a recent WGD occurred 30-45 MYA (Ks 0.15-0.3) and an ancient WGD from a $\gamma$ event occurred 140 MYA (Ks 1.5-1.8) [34]. However, since the divergence of the Rosoideae, Maloideae and Prunoideae subfamilies, the recent lineage-specific WGD event only occurred in the Maloideae (Fig. 1). There were more members of the $\mathrm{Gy}$ subunit gene in members of the Maloideae than in both the Rosoideae and the Prunoideae combined. Therefore, we could infer that the recent WGD event played a crucial role in the expansion of the Gy subunit gene family in the Maloideae.

Sequence features of the Gy subunit genes in the Rosaceae Characteristics of the $\mathrm{G} \gamma$ subunit protein were investigated using the Expasy server, in order to better understand the structures and functions of the Gy subunit genes in the Rosaceae. The results showed that the lengths of the amino acid (aa) sequences ranged from 81 to 265 aa, with most of them being between 104 and 146 (Table 1). The protein molecular weights ranged from 9.10 to $24.06 \mathrm{kDa}$, and the isoelectric points (pI) varied from 4.25 to 10.02 . The isoelectric point value of $68.57 \%$ of the Gy subunit proteins was less than 7 , which indicated that these proteins were rich in acidic amino acids. In addition, the grand average of hydropathicity index (GRAVY) of each protein was calculated, reflecting their hydrophobicity or hydrophilicity,

\begin{tabular}{l} 
Pubus occidentalis \\
\cline { 3 - 5 }
\end{tabular}


Table 1 Characteristics of the Gy subunit proteins in the eight Rosaceae species

\begin{tabular}{|c|c|c|c|c|c|c|c|}
\hline Gene name & Subfamily & $\begin{array}{l}\text { protein } \\
\text { length (aa) }\end{array}$ & $\begin{array}{l}\text { Protein } \\
\text { molecular weight } \\
\text { (Da) }\end{array}$ & $\mathrm{PI}$ & GRAVY & Formula & Aliphatic index \\
\hline FvH4_1g08850.1 & III & 225 & 24063.86 & 9.06 & 0.089 & $\mathrm{C}_{1070} \mathrm{H}_{1720} \mathrm{~N}_{310} \mathrm{O}_{303} \mathrm{~S}_{9}$ & 98.4 \\
\hline FvH4_4g01800.1 & I & 81 & 9100.18 & 4.93 & -0.774 & $\mathrm{C}_{386} \mathrm{H}_{638} \mathrm{~N}_{114} \mathrm{O}_{133} \mathrm{~S}_{3}$ & 77.16 \\
\hline FvH4_2g30640.1 & $\|$ & 125 & 13504.09 & 5.9 & -0.52 & $\mathrm{C}_{584} \mathrm{H}_{927} \mathrm{~N}_{175} \mathrm{O}_{186} \mathrm{~S}_{4}$ & 73.44 \\
\hline MD13G1202200 & । & 105 & 12019.55 & 5.38 & -0.849 & $\mathrm{C}_{523} \mathrm{H}_{830} \mathrm{~N}_{150} \mathrm{O}_{165} \mathrm{~S}_{5}$ & 68.86 \\
\hline MD15G1110600 & ॥ & 129 & 13889.39 & 5.46 & -0.549 & $\mathrm{C}_{607} \mathrm{H}_{946} \mathrm{~N}_{178} \mathrm{O}_{193} \mathrm{~S}_{2}$ & 71.86 \\
\hline MD15G1218900 & III & 211 & 23778.15 & 8.68 & -0.256 & $\mathrm{C}_{994} \mathrm{H}_{1574} \mathrm{~N}_{300} \mathrm{O}_{282} \mathrm{~S}_{48}$ & 44.83 \\
\hline MD03G1256500 & I & 112 & 12197.54 & 4.29 & -0.378 & $\mathrm{C}_{525} \mathrm{H}_{836} \mathrm{~N}_{148} \mathrm{O}_{178} \mathrm{~S}_{4}$ & 87.86 \\
\hline MD16G1202400 & 1 & 105 & 12048.59 & 5.36 & -0.789 & $\mathrm{C}_{524} \mathrm{H}_{833} \mathrm{~N}_{151} \mathrm{O}_{165} \mathrm{~S}_{5}$ & 72.57 \\
\hline MD08G1133500 & $\|$ & 130 & 14162.69 & 5.16 & -0.647 & $\mathrm{C}_{617} \mathrm{H}_{961} \mathrm{~N}_{181} \mathrm{O}_{197} \mathrm{~S}_{3}$ & 69.85 \\
\hline MD11G1277200 & I & 115 & 12511.96 & 4.27 & -0.319 & $\mathrm{C}_{544} \mathrm{H}_{862} \mathrm{~N}_{150} \mathrm{O}_{180} \mathrm{~S}_{4}$ & 92.35 \\
\hline MD02G1093600 & III & 227 & 25213.02 & 8.54 & -0.078 & $\mathrm{C}_{1046} \mathrm{H}_{1669} \mathrm{~N}_{311} \mathrm{O}_{301} \mathrm{~S}_{56}$ & 48.55 \\
\hline Pav_sc0000129.1_g1210.1.mk & III & 218 & 23623.71 & 9.48 & 0.302 & $\mathrm{C}_{1082} \mathrm{H}_{1696} \mathrm{~N}_{294} \mathrm{O}_{282} \mathrm{~S}_{9}$ & 97.52 \\
\hline Pav_sc0000983.1_g380.1.mk & 1 & 113 & 12246.75 & 4.72 & -0.275 & $\mathrm{C}_{530} \mathrm{H}_{851} \mathrm{~N}_{153} \mathrm{O}_{172} \mathrm{~S}_{4}$ & 92.39 \\
\hline Pav_sc0003562.1_g080.1.mk & ॥ & 143 & 15719.31 & 5.78 & -0.774 & $\mathrm{C}_{681} \mathrm{H}_{1058} \mathrm{~N}_{204} \mathrm{O}_{220} \mathrm{~S}_{3}$ & 62.8 \\
\hline Pm004925 & $\|$ & 142 & 15470.98 & 5.78 & -0.824 & $\mathrm{C}_{664} \mathrm{H}_{1042} \mathrm{~N}_{202} \mathrm{O}_{220} \mathrm{~S}_{3}$ & 62.54 \\
\hline Pm020240 & 1 & 112 & 12257.64 & 4.43 & -0.362 & $\mathrm{C}_{526} \mathrm{H}_{844} \mathrm{~N}_{152} \mathrm{O}_{177} \mathrm{~S}_{4}$ & 90.54 \\
\hline Pm027095 & III & 206 & 22507.71 & 9.42 & 0.219 & $\mathrm{C}_{1014} \mathrm{H}_{1623} \mathrm{~N}_{279} \mathrm{O}_{267} \mathrm{~S}_{16}$ & 94.08 \\
\hline Prupe.2G330000.1.p & $\|$ & 146 & 15970.54 & 5.66 & -0.793 & $\mathrm{C}_{687} \mathrm{H}_{1079} \mathrm{~N}_{205} \mathrm{O}_{229} \mathrm{~S}_{3}$ & 63.56 \\
\hline Prupe.8G233500.1.p & I & 113 & 12286.64 & 4.43 & -0.384 & $\mathrm{C}_{526} \mathrm{H}_{843} \mathrm{~N}_{153} \mathrm{O}_{178} \mathrm{~S}_{4}$ & 88.05 \\
\hline Prupe.1G462900.1.p & $\|$ & 146 & 15859.4 & 5.78 & -0.787 & $\mathrm{C}_{680} \mathrm{H}_{1070} \mathrm{~N}_{206} \mathrm{O}_{227} \mathrm{~S}_{3}$ & 62.88 \\
\hline Prupe.1G024000.1.p & I & 105 & 11993.51 & 5.41 & -0.842 & $\mathrm{C}_{520} \mathrm{H}_{828} \mathrm{~N}_{152} \mathrm{O}_{164} \mathrm{~S}_{5}$ & 68.86 \\
\hline Prupe.7G197000.1 & III & 234 & 26038.81 & 8.6 & -0.174 & $\mathrm{C}_{1074} \mathrm{H}_{1704} \mathrm{~N}_{324} \mathrm{O}_{314} \mathrm{~S}_{58}$ & 42.95 \\
\hline Pbr012894.1 (PbrGG1) & I & 114 & 12512.87 & 4.25 & -0.41 & $\mathrm{C}_{541} \mathrm{H}_{853} \mathrm{~N}_{151} \mathrm{O}_{182} \mathrm{~S}_{4}$ & 86.32 \\
\hline Pbr014702.1 (PbrGG2) & 1 & 105 & 12019.55 & 5.38 & -0.849 & $\mathrm{C}_{523} \mathrm{H}_{830} \mathrm{~N}_{150} \mathrm{O}_{165} \mathrm{~S}_{5}$ & 68.86 \\
\hline Pbr018868.1 (PbrGG3) & 1 & 129 & 14720.6 & 5.64 & -0.769 & $\mathrm{C}_{635} \mathrm{H}_{1024} \mathrm{~N}_{186} \mathrm{O}_{204} \mathrm{~S}_{6}$ & 72.71 \\
\hline Pbr002651.1 (PbrGG4) & ॥ & 132 & 14027.51 & 5.26 & -0.505 & $\mathrm{C}_{613} \mathrm{H}_{952} \mathrm{~N}_{180} \mathrm{O}_{195} \mathrm{~S}_{2}$ & 73.94 \\
\hline Pbr021253.1 (PbrGG5) & $\|$ & 129 & 13959.55 & 4.99 & -0.487 & $\mathrm{C}_{608} \mathrm{H}_{952} \mathrm{~N}_{176} \mathrm{O}_{194} \mathrm{~S}_{4}$ & 74.88 \\
\hline Pbr027751.1 (PbrGG6) & III & 204 & 22757.6 & 10.02 & -0.013 & $\mathrm{C}_{1035} \mathrm{H}_{1641} \mathrm{~N}_{297} \mathrm{O}_{270} \mathrm{~S}_{6}$ & 95.59 \\
\hline Pbr037429.2 (PbrGG7) & III & 209 & 23449.94 & 8.66 & -0.187 & $\mathrm{C}_{976} \mathrm{H}_{1562} \mathrm{~N}_{294} \mathrm{O}_{277} \mathrm{~S}_{50}$ & 49 \\
\hline pycom02g07380 & III & 265 & 29871.49 & 8.59 & 0.016 & $\mathrm{C}_{1292} \mathrm{H}_{2000} \mathrm{~N}_{362} \mathrm{O}_{348} \mathrm{~S}_{53}$ & 57.02 \\
\hline pycom03g20330 & I & 114 & 12624.01 & 4.34 & -0.472 & $\mathrm{C}_{546} \mathrm{H}_{862} \mathrm{~N}_{154} \mathrm{O}_{182} \mathrm{~S}_{4}$ & 84.56 \\
\hline pycom 1 1g24520 & 1 & 114 & 12437.89 & 4.43 & -0.392 & $\mathrm{C}_{540} \mathrm{H}_{856} \mathrm{~N}_{152} \mathrm{O}_{177} \mathrm{~S}_{4}$ & 87.19 \\
\hline pycom15g19410 & III & 211 & 23694.15 & 8.7 & -0.245 & $\mathrm{C}_{983} \mathrm{H}_{1574} \mathrm{~N}_{300} \mathrm{O}_{281} \mathrm{~S}_{50}$ & 46.68 \\
\hline Ro02_G04020 & I & 104 & 11699.13 & 4.35 & -0.332 & $\mathrm{C}_{508} \mathrm{H}_{814} \mathrm{~N}_{140} \mathrm{O}_{168} \mathrm{~S}_{4}$ & 97.5 \\
\hline Ro01_G03005 & III & 248 & 27144.88 & 9.2 & 0.298 & $\mathrm{C}_{1232} \mathrm{H}_{1975} \mathrm{~N}_{343} \mathrm{O}_{329} \mathrm{~S}_{9}$ & 112.42 \\
\hline
\end{tabular}

by calculating the sum of the hydropathy values of all the amino acids divided by the sequence length [35]. The results showed that the GRAVY value of $85.71 \%$ of the $\mathrm{G} \gamma$ subunit proteins was less than 0 , indicating that these proteins were hydrophilic. Finally, the aliphatic index of the $\mathrm{G} \gamma$ subunit proteins in the eight Rosaceae species was analyzed, with the results showing that most of them were quite variable. The aliphatic indices of the $\mathrm{G} \gamma$ subunit proteins ranged from 42.95 to 112.42 , which indicated that these $\mathrm{G}$ r subunit proteins were thermostable (Table 1).
Classification, gene structure and conserved protein motif analysis of $G y$ subunits in members of the Rosaceae

To classify the $\mathrm{G} \gamma$ subunit genes identified in members of the Rosaceae, in order to investigate their evolutionary relationships, a phylogenetic tree was constructed, based on the protein sequences, using the NeighborJoining (NJ) method. Based on the phylogenetic tree, the $\mathrm{G} \gamma$ subunit genes in eight rosaceous species were divided into three types (I, II and III) (Fig. 2A). Subsequently, the structural diversity of $\mathrm{G} \gamma$ subunit genes was analyzed by comparing the numbers of introns and 


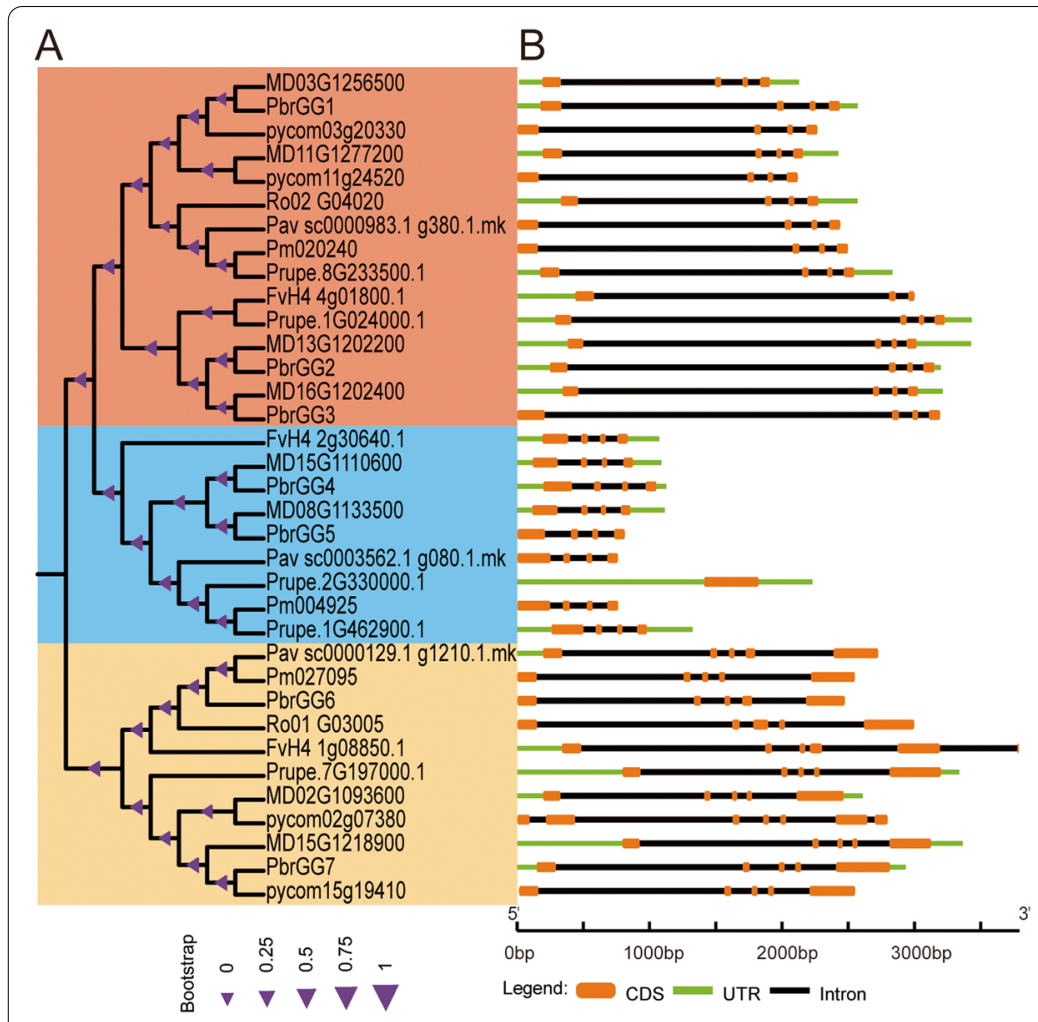

Fig. 2 Phylogenetic tree, structural gene features and conserved protein motifs of the Gy subunit genes in the eight Rosaceae species. A The phylogenetic tree was generated using the amino acid sequences encoded by each of $35 \mathrm{G} \gamma$ subunit genes with the Neighbor-Joining method and 1,000 bootstrap replicates. Different colors in the branches indicated the different subunit type. B Gene structural analysis, the orange boxes, black lines and green boxes in the gene structural diagram represent coding sequences (CDS), introns and untranslated regions (UTRs), respectively; gene models are drawn to scale as indicated on the $\mathrm{x}$-axis. C Conserved motif analysis: fifteen distinct motifs (motifs 1 to 15) were identified with the MEME tool and the representation of each motif was illustrated with a different color. The lengths and positions of the colored blocks correspond to the lengths and positions of the motifs in the individual protein sequences, respectively

exons. The results showed that there was no significant difference in the number of exons in each type, with the number of exons in types I and II being the same, namely four exons, except for $\mathrm{FvH}_{-}$4g01800.1 (three) and Prupe.2G330000.1(one) (Fig. 2B). However, the number of exons in type III was slightly higher than that in types I and II, namely five exons, except for FvH4 1 g08850.1 (six) and pycom02g07380 (seven).

In order to further investigate the diversity of $\mathrm{G} \gamma$ subunit gene structure and function in each type, we performed conserved motif analysis on the Gy subunit protein sequences in the eight Rosaceae species, using the MEME program. The results showed that 15 consensus motifs were identified, namely motif $1-15$ (Fig. 2C). The number of motifs present in the $\mathrm{G} \gamma$ subunit protein sequences of each type was variable, ranging from two to seven. Among them, the members of type I had the fewest conserved motifs, which ranged from two to five, with motifs 1 and 2 being present in all the Gy subunit proteins of type I. Members of clade II contained an intermediate number of conserved motifs, which ranged from four to six, with motifs $1,2,8$ and 10 being universally distributed in the Gy subunit protein family of type II. Type III contained the highest number of conserved motifs, with the largest number in a single protein being seven, with motifs 1 and 11 being present in all the Gy subunit proteins of type III. Therefore, motif 1 was determined to be the conserved domain of the Gy subunit protein based on the above results from the conserved motif analysis, because it was identified in all 35 members of the Gy subunit protein family of the Rosaceae. The phylogenetic relationship, structural diversity and conserved motif analysis of the Gy subunit proteins showed that the conservation and specificity of the number of conserved motifs and exons in different subunit types may have originated via different evolutionary paths and may play varying functions in different organs. 
Evolutionary expansion of gene number and syntenic analysis of Gy subunit genes in the Rosaceae

Gene duplication events contribute to the expansion of protein-coding gene families, consisting of five classes of gene duplication events, namely WGD (whole-genome duplication), dispersed, tandem, proximal and singleton duplications. To explore the evolutionary origins of the members of the $\mathrm{Gr}$ subunit gene family in the Rosaceae, the duplication events occurring during evolution of the $\mathrm{G}$ y subunit gene family in the eight species of the Rosaceae were analyzed. Overall, three of the five classes of gene duplication events (WGD, singleton and dispersed) were identified in evolution of the $\mathrm{Gr}$ subunit gene family in the Rosaceae species, with $20 \%, 62.9 \%$ and $17.1 \%$ of the $\mathrm{G} \gamma$ subunit genes in the Rosaceae being duplicated and retained as a result of a singleton event, a WGD event, or a dispersed event, respectively (Fig. 3). More specifically, a WGD event was found to be responsible for expansion of only the $G \gamma$ subunit gene family in Chinese white pear, apple and European pear, which infers that the WGD event plays an important role in the expansion and evolution of the $\mathrm{G} \gamma$ subunit gene family in only the Maloideae subfamily. In strawberry, only a singleton event was identified as being responsible for the expansion of the Gy subunit gene family. Furthermore, $20 \%, 33.3 \%, 50 \%$ and $33.3 \%$ of the Gy subunit genes were duplicated and retained from singleton events in peach, Japanese apricot, black raspberry and sweet cherry, respectively; 20, 33.3 and $50 \%$ of the Gy subunit genes were duplicated and retained from a WGD event in peach, Japanese apricot, and black raspberry, respectively; and $60,33.3$ and $66.7 \%$ Gy subunit genes were duplicated and retained from dispersed events in peach, Japanese apricot and sweet cherry, respectively (Table S1).

To investigate the evolutionary roles and to better understand the diversity of the $\mathrm{G} \gamma$ subunit gene family, we analyzed the syntenic relationships among the $\mathrm{G} \gamma$ subunit genes of the eight Rosaceae species. In this study, each of the $35 \mathrm{G}$ y subunit genes could be anchored to the chromosomes of one of the rosaceous species. Seven $\mathrm{G} \gamma$ subunit genes were mapped onto six of the 17 chromosomes in Chinese white pear, and four $\mathrm{Gr}$ subunit genes were assigned to Chr2, Chr3, Chr11, and Chr15 in European pear. Two Gy subunit genes were located on two of the six chromosomes in black raspberry, and three $\mathrm{Gy}$ subunit genes were distributed on Chr1, Chr2 and Chr4 in strawberry. Eight $\mathrm{G} \gamma$ subunit genes were located to seven of the 17 chromosomes in apple, whereas three $\mathrm{Gr}$ subunit genes were located on Chr1, Chr7 and Chr8 in sweet cherry. Three Gy subunit genes were distributed on three of the eight chromosomes of Japanese apricot, while five $\mathrm{G}$ y subunit genes were located on Chr1, Chr2, Chr7 and Chr8 in peach (Fig. 4).

Synteny and collinearity are traditionally determined by searching for both inter- and intragenomic pairwise conservation blocks, and the maximum synteny was observed in apple, which contained eight $\mathrm{G} \gamma$ subunit genes that were syntenic with $34 \mathrm{G} \gamma$ subunit genes among the eight Rosaceae species. In Chinese white pear, we also found that seven $G \gamma$ subunit genes were syntenic with $55 \mathrm{G} \gamma$ subunit genes among the eight Rosaceae species. In addition, 39, 33, 32, 27, 22 and 21 gene pairs showing collinear relationships were obtained in European pear, peach, sweet cherry, Japanese apricot, strawberry and black raspberry, respectively (Fig. 4).

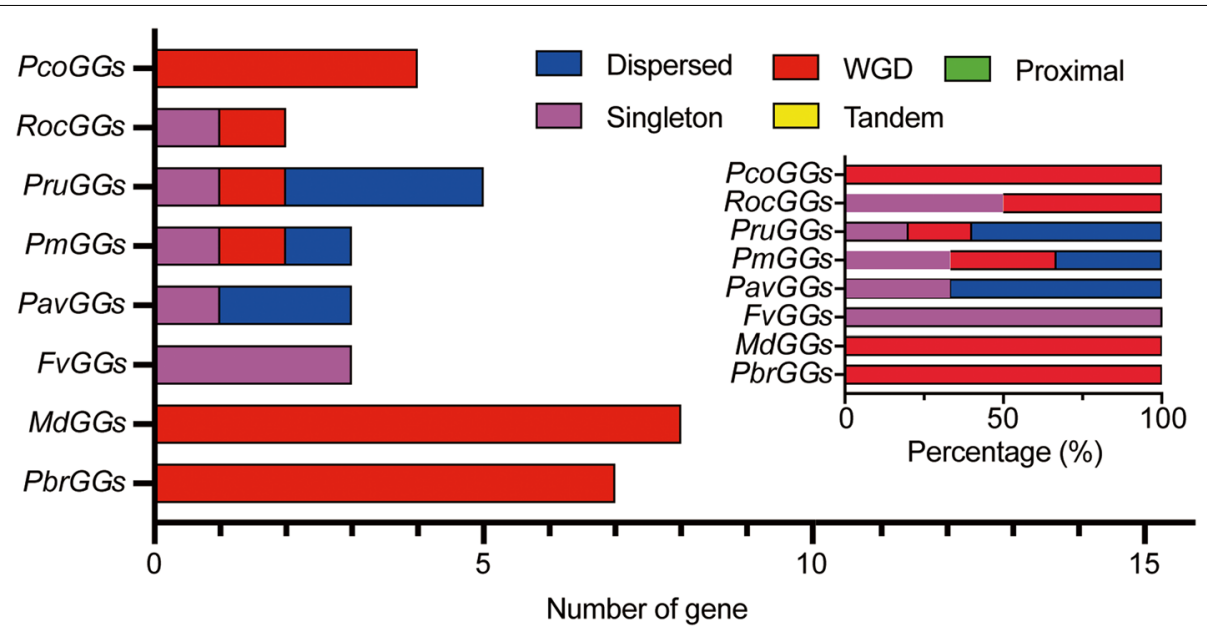

Fig. 3 The number of Gy subunit gene pairs from different origins in the eight Rosaceae species. The number of different modes of duplicated Gy subunit gene pairs was determined by MCScanX and presented by GraphPad Prism 8 software. The X-axis in the lower histogram indicates the number of Gy subunit genes. The $x$-axis of the upper-right histogram indicates the percentage frequency of each duplicated event. The $y$-axis of both histograms indicates the different species. Different color bars represent different duplication events 


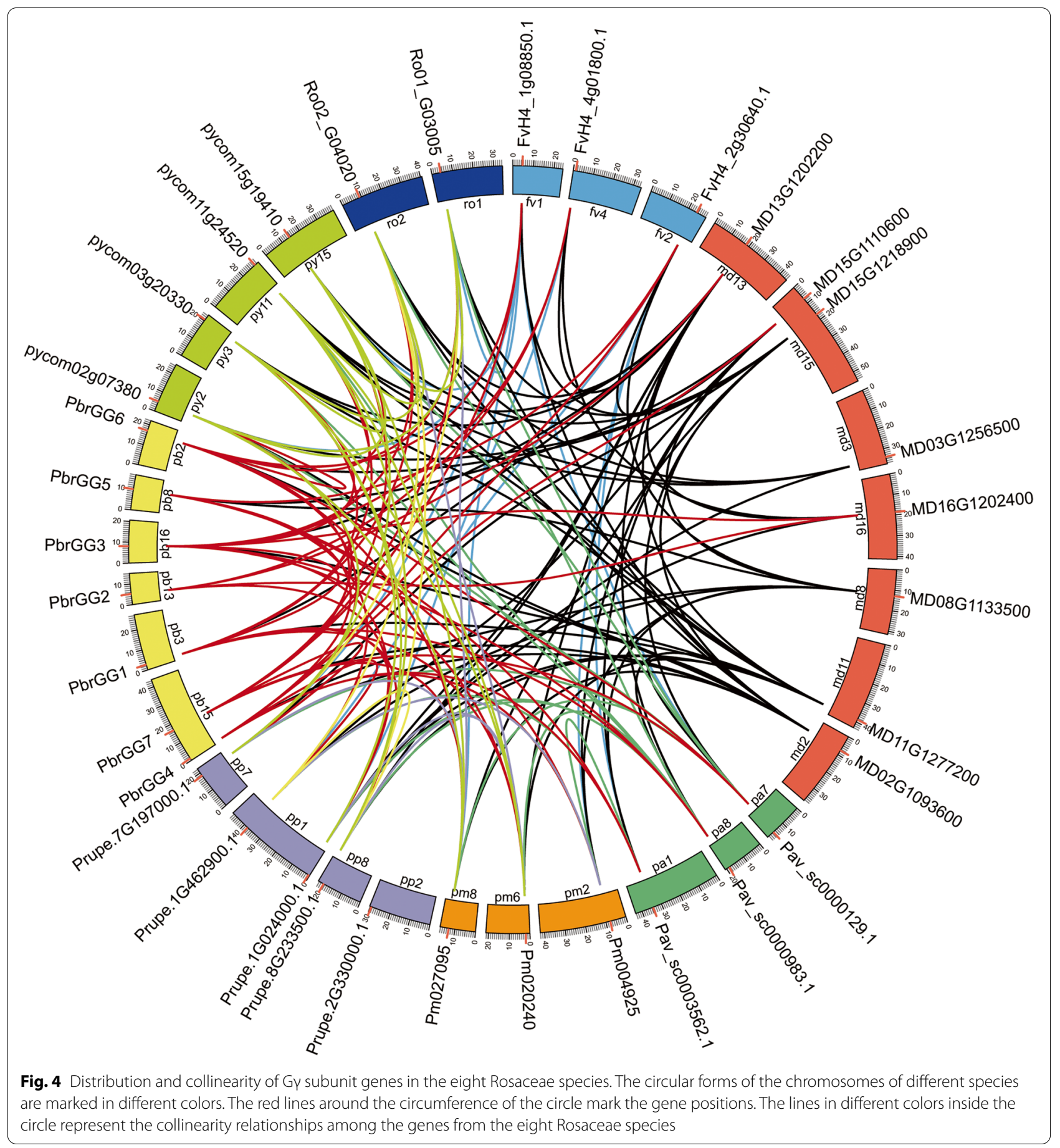

\section{Ks value and $\mathrm{Ka} / \mathrm{Ks}$ ratio analysis of $\mathrm{G} \gamma$ subunit genes in the Rosaceae}

The Ks value is commonly used to estimate the approximate occurrence dates of whole-genome duplication or segmental duplication events. According to previous research, two WGD events occurred in the Chinese white pear and apple genomes, one of them being an ancient WGD event (Ks 1.5-1.8 in pear, and Ks 1.6 in apple) which happened about 140 mya, whereas the other was the recent WGD event (Ks 0.15-0.3 in pear, and Ks 0.2 in apple), which occurred about 30-45 mya [34]. To estimate the evolutionary dates of WGD events, the mean Ks of the Gy subunit duplicated gene pairs on each side flanking region were analyzed in the Rosaceae species. The results showed that the mean Ks values for the Gy subunit gene pairs ranged from 0.17 to 1.53 (Fig. 5A 

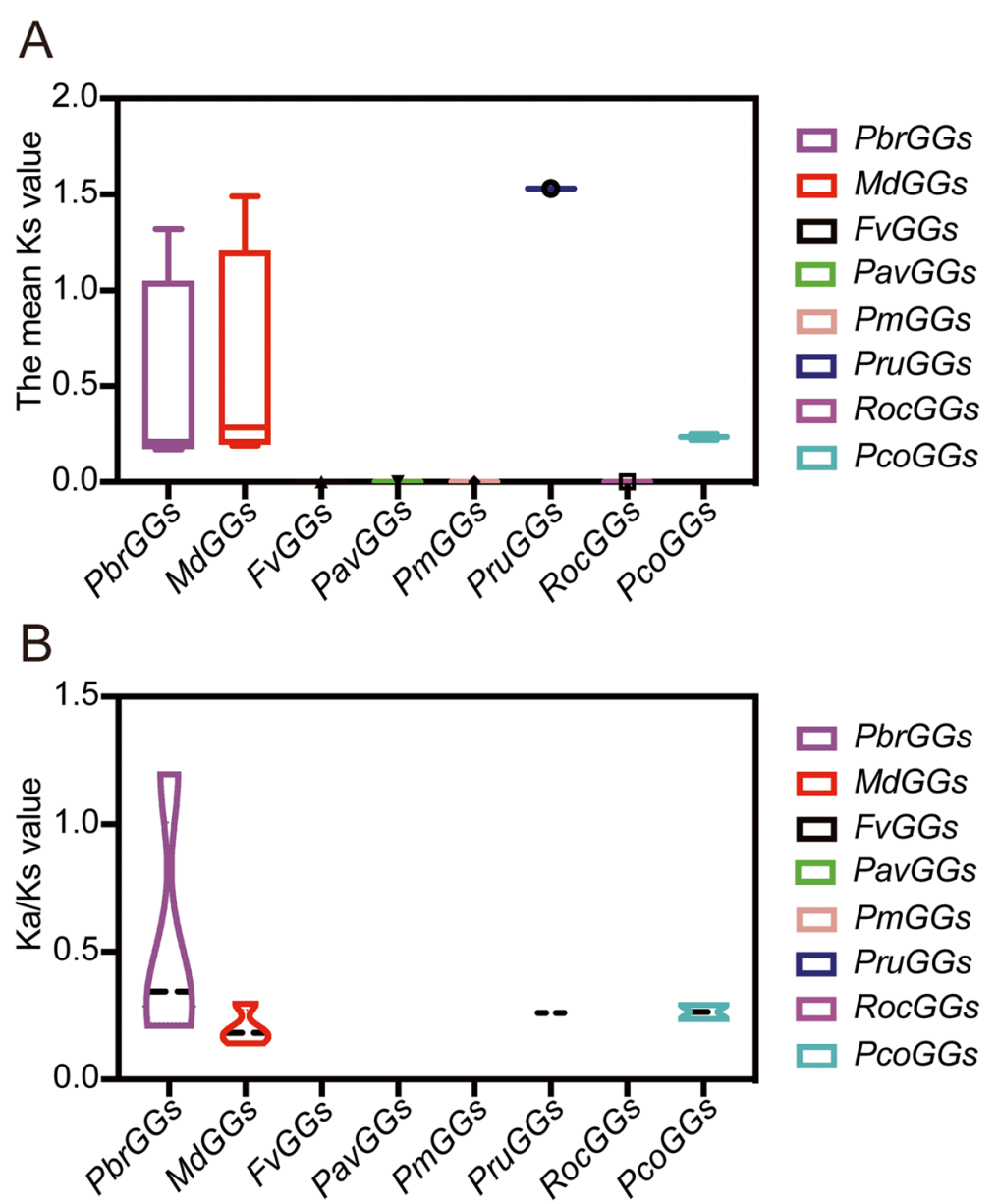

Fig. 5 Distribution of the mean $\mathrm{Ks}$ and $\mathrm{Ka} / \mathrm{Ks}$ values of $\mathrm{G} \gamma$ subunit genes in the eight Rosaceae species. A The mean $\mathrm{Ks}$ values represent the times of Gy subunit gene divergence in the eight Rosaceae species. B Ka/Ks ratios represent the driving forces behind duplicated Gy subunit gene evolution in the eight Rosaceae species

and Table S2). We further determined that the WGD event for the Chinese white pear gene pair PbrGG4 and PbrGG5 (Ks 0.23), the apple gene pairs MD02G1093600 and MD15G1218900 (Ks 0.17) and MD13G1202200 and MD16G1202400 (Ks 0.18) may have arisen from the recent WGD event, taking place about 30-45 mya. Some duplicated gene pairs possessed similar but higher Ks values, such as PbrGG3 and PbrGG1 (Ks 1.9), indicating that these duplications may have been derived from the same, ancient WGD event, which occurred approximately $\sim 140$ mya. In addition, one duplicated apple gene pair (MD11G1277200 and MD13G1202200) had an even higher $\mathrm{Ks}$ value $(\mathrm{Ks} \sim 2.1)$, suggesting that they might have resulted from an even more ancient duplication event. Furthermore, orthologous pairs and divergence time of Gy subunit genes among the eight Rosaceae species were analyzed by analyzing syntenic relationships. The results showed that the number of orthologous gene pairs identified between Chinese white pear and the other seven Rosaceae species, namely strawberry, apple, sweet cherry, Japanese apricot, peach, European pear and black raspberry was six, fourteen, six, six, eight, eight and four, respectively (Table S3). The average Ks values of the $\mathrm{G} \gamma$ subunit orthologs between Chinese white pear and strawberry, apple, sweet cherry, Japanese apricot, peach, European pear and black raspberry ranged from 0.01 to 2.31 (Table S3). The divergence time of the Gy subunit genes for Chinese white pear and European pear ranged from 0.47 to 71.95 mya, moreover, the divergence time for Chinese white pear and the other six Rosaceae species was between 1.93 and 77.00 mya (Table S3). Among them, the Gy subunit orthologs between Chinese white pear and apple had the lowest average Ks value (Ks 0.51 ), indicating that the $G \gamma$ subunit gene evolutionary distance between these two species was closest among the eight Rosaceae species, whereas the Gy subunit ortholog gene pairs between Chinese white pear and black raspberry exhibited the highest average Ka value 
(Ks 0.81) (Table S3), signifying the most distant evolutionary distance.

To further explore which selection process drove the evolution of the Gy subunit gene family, the $\mathrm{Ka} / \mathrm{Ks}$ values of the paralogous $\mathrm{G} \gamma$ subunit genes between the interand intragenomic pairwise blocks were analyzed in the eight Rosaceae species. Previous studies had shown that a $\mathrm{Ka} / \mathrm{Ks}$ value greater than 1 indicates Darwinian (positive) selection, whereas a $\mathrm{Ka} / \mathrm{Ks}$ value equal to 1 indicates neutral evolution, and a $\mathrm{Ka} / \mathrm{Ks}$ value less than 1 indicates purifying (negative) selection [36]. Purifying selection is a process that can eliminate some disadvantageous mutations, whereas Darwinian selection can accumulate some new advantageous mutations and spread them throughout future generations. In the present study, the $\mathrm{Ka} / \mathrm{Ks}$ value of most of the $\mathrm{Gr}$ subunit orthologous gene pairs was less than 1 , indicating that purifying selection was the main factor driving the evolution of the Gy subunit gene family in the Rosaceae (Fig. 5B, Table S3). Surprisingly, two duplicated gene pairs (PbrGG6 and pycom02g07380, PbrGG7 and PbrGG6) showed higher $\mathrm{Ka} / \mathrm{Ks}$ values $(>1)$, suggesting that they might have undergone Darwinian selection (Fig. 5B, Table S3).

\section{Expression pattern analysis of $P b r G G$ genes in different organs}

To explore the specific expression patterns and possible functional characteristics in various organs, seven $P b r G G$ genes from Chinese white pear were chosen as candidate genes with which to establish a real-time quantitative PCR (qPCR) study to analyze the relative expression levels in root, stem, leaf, fruit, petal, sepal, ovary, bud, pollen and pollen tube of Chinese white pear. The results showed that the seven $\mathrm{PbrGG}$ genes exhibited a diversity of expression levels in different pear organs, suggesting that $\mathrm{G} \gamma$ subunit genes may perform specific functions in different organs, participating in the corresponding metabolic processes. Overall, most of Gy subunit genes were preferentially expressed in root, fruit, petal, ovary and bud tissues, indicating that Gy subunit genes may play an important role in the growth and development of these organs. Specifically, PbrGG4 was expressed at high levels in the fruit and root, but relatively weakly in the stem and the leaf, whereas PbrGG1 and PbrGG7 were highly expressed in the ovary, in addition to their expression in sepal and bud. The expression levels of PbrGG2 in root, stem, petal, sepal and ovary were significantly higher than those in leaf, fruit and bud whereas PbrGG3 expression showed preferential upregulation in the root, stem, leaf and bud whereas PbrGG6 showed preferential expression in the fruit and the bud, with the expression levels of PbrGG5 being upregulated not only in the root, leaf and petal but also in the pollen and the stem (Fig. 6).

\section{Expression patterns of PbrGG genes under abiotic stress} To further explore the potential functions of $P b r G G s$ in response to various abiotic stress, pear seedlings were treated with nitrogen deficiency (N-deficiency) and ABA, and the relative expression levels of these genes were checked by qRT-PCR. The results showed that exposure to $\mathrm{N}$-deficiency stress caused the relative expression levels of $\mathrm{PbrGG3}$, and $\mathrm{PbrGG6}$ to increase by $\sim 2.6$ and $\sim 3.8$-folds in roots after five days as compared to $C K$, respectively; while $\mathrm{PbrGG1}$ PbrGG2, $\mathrm{PbrGG4}$, $\mathrm{PbrGG5}$, and $P b r G G 7$ showed no significant changes in root under $\mathrm{N}$-deficiency stress (Fig. 7A). Furthermore, in response to exogenous ABA treatment, each $P b r G G$ genes showed a differential expression pattern. For example, PbrGG1, PbrGG3 and PbrGG5 were mainly up-regulated in leaves under ABA treatments (Fig. 7B). The expression levels of PbrGG4 were significantly down-regulated after ABA treatment (Fig. 7B). However, the expression levels of $P b r G G 2, P b r G G 6$ and $P b r G G 7$ remained unchanged after ABA treatment (Fig. 7B). These results suggest that the expression levels of $P b r G G$ genes were induced by $\mathrm{N}$-deficiency or $\mathrm{ABA}$ treatment and therefor may be involved in regulation of these biological processes responses related to it.

\section{Subcellular localization of PbrGG proteins in Chinese white pear}

To further investigate the functions of the $G y$ subunit genes in members of the Rosaceae, seven PbrGG genes were chosen as candidate genes with which to explore subcellular localization. Based on the presence of targeted sequences in the protein, the predictive results from the WoLF PSORT software showed that most of the $G$ y subunit proteins were predicted to be located on the plasma membrane, in the nucleus and/or cytoplasm (Table S4). Seven Gy subunit genes from different types were then selected to test the results of subcellular localization prediction experimentally, using transient expression assays of fusion proteins between the $\mathrm{G} \gamma$ subunit and the reporter green fluorescent protein (GFP). The recombinant plasmid of 35s::PbrGG-GFP and control plasmid of $35 \mathrm{~s}-G F P$ were transformed into Nicotiana benthamiana leaves by the Agrobacterium-mediated method. The results showed that the experiment data are basically identical with the WoLF PSORT software predicted ones. Using laser confocal microscopy, the green fluorescence was seen to be distributed across the entire cell when the control plasmid was used to transform the Nicotiana benthamiana leaves (Fig. 8). For tobacco cells transformed with the recombinant plasmids, however, the green fluorescence of PbrGG1-GFP from type I was observed on the plasma membrane and in the cytoplasm while that of PbrGG2-GFP and PbrGG3-GFP were 

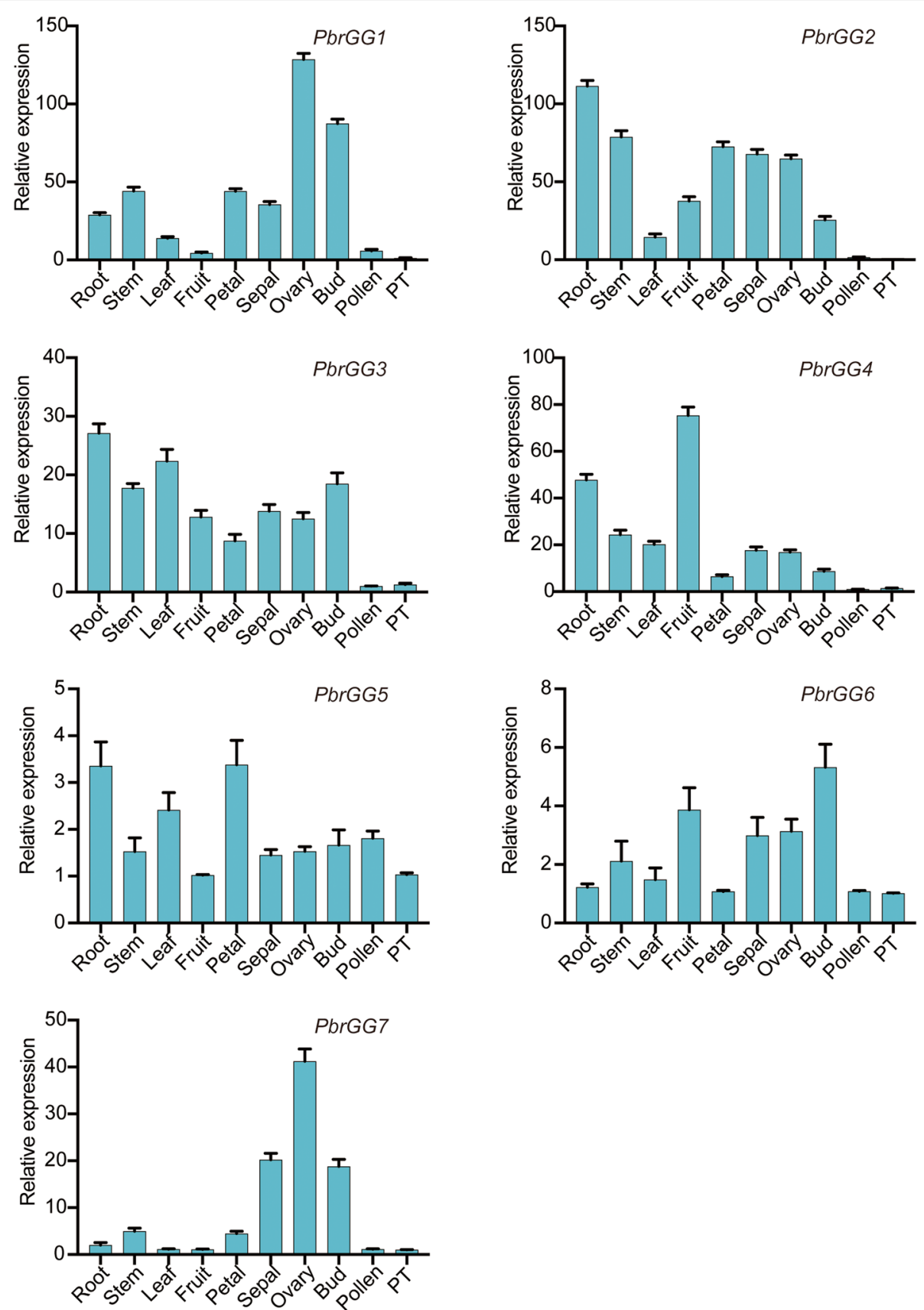

Fig. 6 Expression analysis of seven PbrGG genes in different tissues. The relative transcript abundance levels of PbrGG genes were assessed by qPCR in various tissues of Chinese white pear. Total RNA was extracted from the root, leaf, stem, petal, bud, sepal, fruit, ovary, pollen and pollen tubes. For each gene, the relative expression levels were obtained by normalization with pear Actin. Data are shown as mean \pm standard deviation

observed only on plasma membrane. PbrGG4-GFP and PbrGG5-GFP from type II were observed on the plasma membrane and in the nucleus, whereas the fusion protein of PbrGG6-GFP and PbrGG7-GFP showed green fluorescence exclusively on the plasma membrane (Fig. 8). Therefore, these results indicated that $\mathrm{G} \gamma$ subunit protein may play an important biological role in particular on the plasma membrane, as well as in the nucleus or cytoplasm depending on the identity of the subunit protein.

\section{Discussion}

The $\mathrm{Gr}$ subunit proteins have been implicated in growth and development processes, including the regulation of seed and organ size, and in signal 

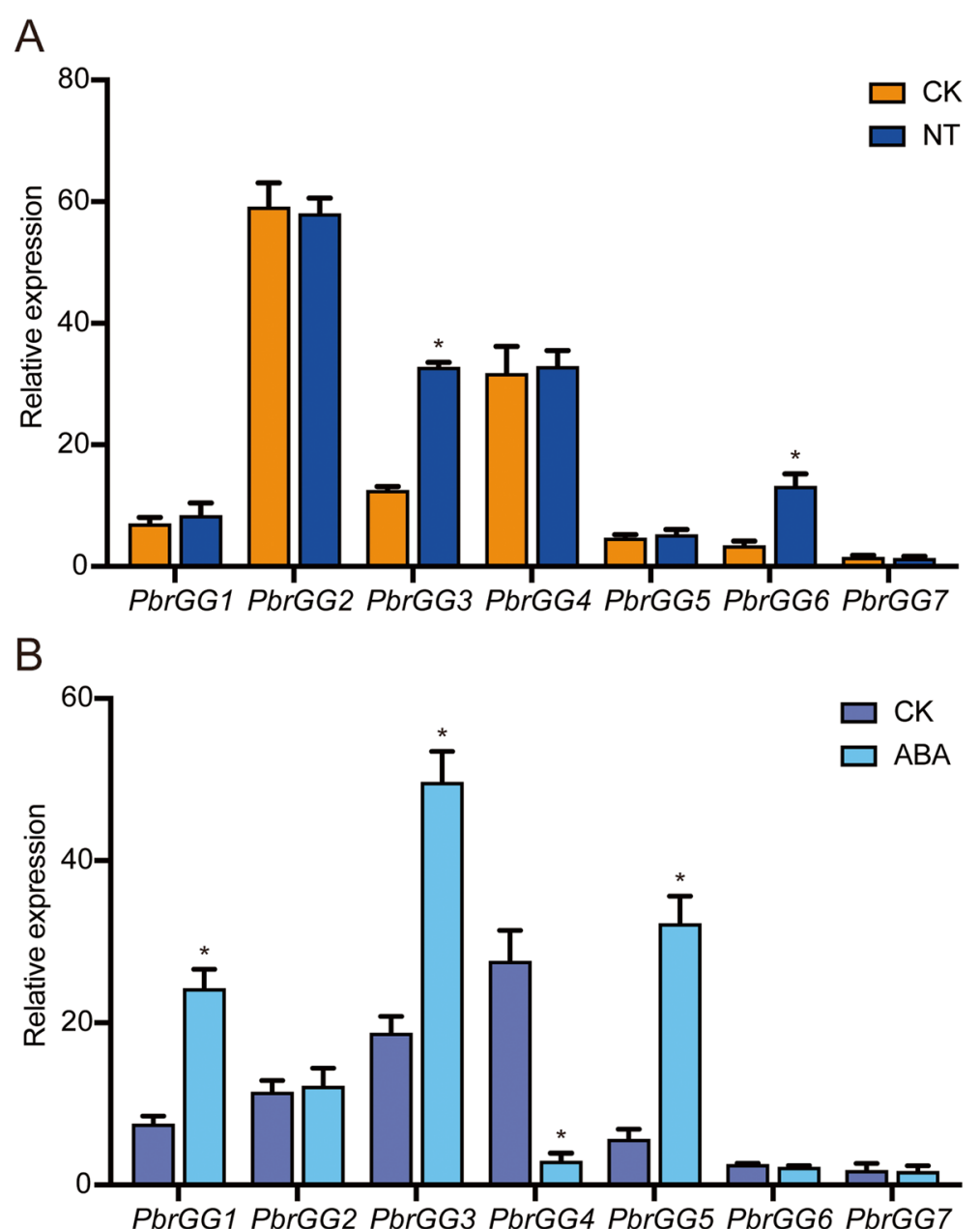

Fig. 7 Expression patterns of $P b r G G$ genes under abiotic stress. The relative expression levels of PbrGG genes were analyzed by qRT-PCR, and the samples were harvested from roots after N-deficiency treatment for five days; and the samples were harvested from leaves after ABA treatment for $6 \mathrm{~h}$. For each gene, the relative expression levels were acquired by normalization to that of pear Actin. The error bars indicate standard deviations. Asterisks indicate a significant difference $\left.{ }^{*} P<0.05\right)$ compared with $C K$ after abiotic stress treatment. Data are expressed as mean \pm standard deviation

transduction, individually or in combination with $G \alpha \beta$. As an important part of G-protein, some members of the $\mathrm{G} \gamma$ subunit protein family have been widely studied in various plants, such as Arabidopsis [37], rice [11], tomato [10] and cucumber [7]. However, there has been little research into annotation of the Gy subunit proteins in members of the Rosaceae. In the current study, a total of $35 \mathrm{Gr}$ subunit genes were identified in eight rosaceous species, with the $\mathrm{Gr}$ subunit gene family in Chinese white pear, European pear and apple having more members than those in strawberry, sweet cherry, peach, black raspberry or Japanese apricot. Furthermore, the number of $\mathrm{G} \gamma$ subunit genes in Chinese white pear, European pear and apple was much higher than that reported in the model plant Arabidopsis [2].
In Fig. 1, we showed that the subfamily Maloideae had undergone both an ancient WGD event and a recent WGD event whereas only one ancient WGD event had occurred in species from the other two subfamilies [34]. These results indicated that the number of Gy subunit genes had been expanded on a small scale by recent WGD events, resulting in an increase in the numbers of Gy subunit genes in the Maloideae. Furthermore, gene duplication analysis showed that the expansion of the $\mathrm{G} \gamma$ subunit genes in Chinese white pear, European pear and apple was due mainly to WGD events, while singleton and dispersed duplication events being identified as the major driving force for expansion of the $G$ y subunit genes in the other Rosaceae species. The Ka/Ks ratios of all paralogous $\mathrm{G} \gamma$ subunit pairs were less than 1, 

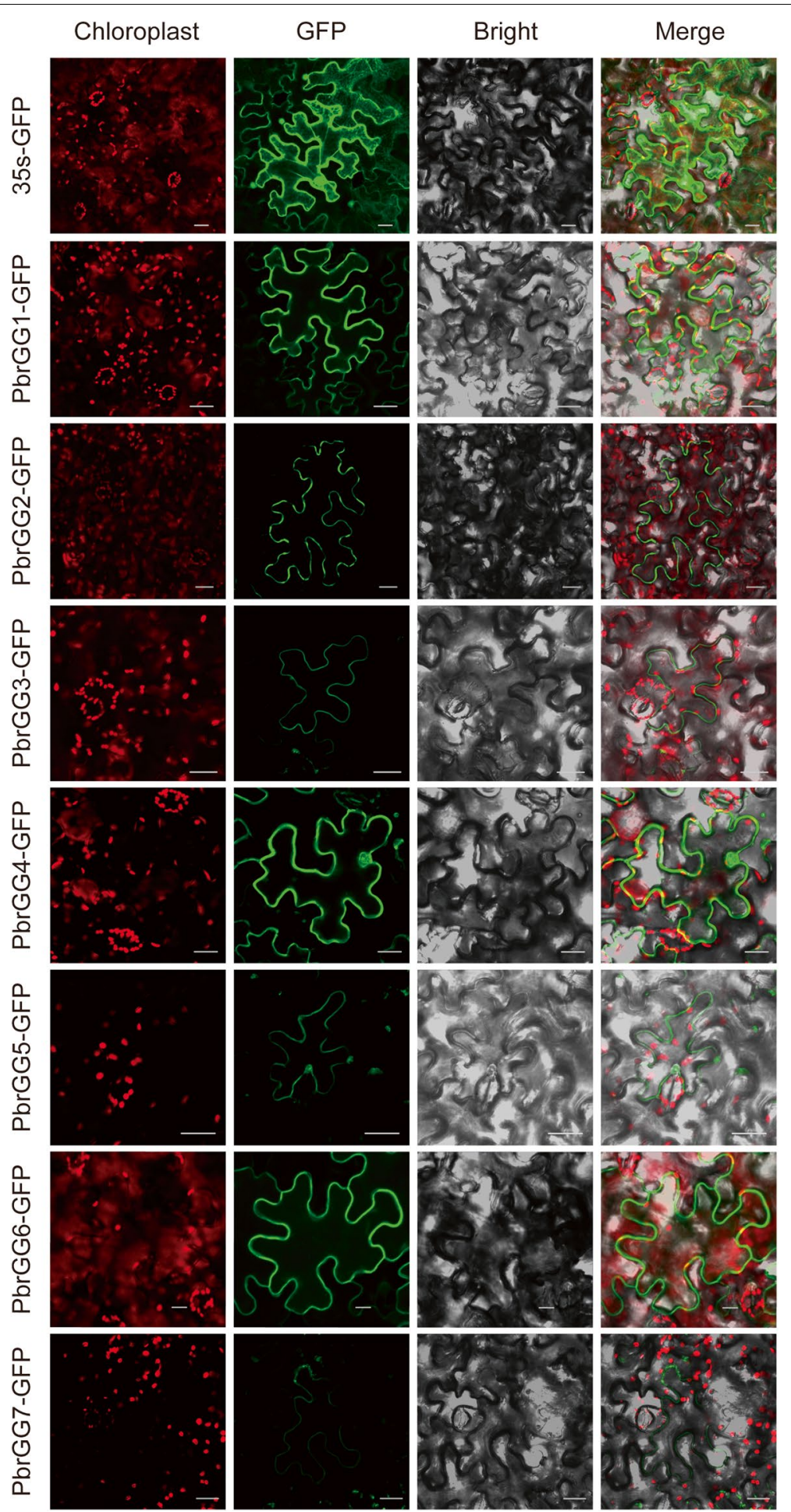

Fig. 8 Subcellular localization of three PbrGG proteins. Seven PbrGG-GFP fusion proteins, with 35s-GFP as the control, were expressed transiently in tobacco leaves in an independent manner, and the results were visualized by laser confocal microscopy. The merged images include the chloroplast autofluorescence channel (first panels) and the green fluorescence channel (second panels). The corresponding brightfield images are shown in the third panels. Bar $=20 \mu \mathrm{m}$ 
suggesting that the Gy subunit genes underwent negative selection during the evolutionary process.

The plant $\mathrm{G} \gamma$ subunit proteins are clearly distinguished into three different types based on their structural characteristics: type I (the classic one, resembling the subunits in animals), type II (lacking the isoprenylation motif) and type III (with a long tail) [10, 16, 38]. To classify and further explore the structural diversity of the $\mathrm{G} \gamma$ subunit genes in Rosaceae, a phylogenetic tree was constructed, as well as analyses based on gene features, gene structures and protein conserved motifs were carried out in the current study. The results from the phylogenetic tree construct showed that all Gy subunit genes were classified into three clades or types in the Rosaceae, namely I, II and III, a finding which is consistent with the classification from previous reports [16]. Furthermore, the results of gene structure and conserved protein motif analyses also supported the classification of the $\mathrm{G} \gamma$ subunit genes in the Rosaceae, except for the loss of introns/exons or motifs in some Gy subunit genes, with the characteristics of the $\mathrm{G} \gamma$ subunit genes being similar within each type and varying among different types. This is consistent with findings from previous studies, among the three Arabidopsis Gy subunit genes, AGG1 and AGG2, belonging to the same type, and strongly resembling the canonical mammalian Gy subunit type I [8, 11, 39]. The type III Gy subunit proteins are almost twice the size of the type I or type II Gy subunits, with the number of amino acids in the type III Gy subunit in the range 204-265, compared with the number of amino acids in the type I or type II Gy subunits which were in the range 81-129, or 125-146 amino acids, respectively. These results resembled those previously reported from Arabidopsis, rice and soybean $[11,12,19,26]$.

Following the isolation and cloning of the first $\mathrm{G} \gamma$ subunit gene from Arabidopsis [8], and with the development of high-throughput sequencing technology, bioinformatics and molecular biology techniques, the expression patterns and functional characteristics of $\mathrm{G} \gamma$ subunits have been widely studied. For example, the type I Gy subunit, represented by AGG1 in Arabidopsis, regulates lateral root formation by affecting the amount of the auxin 1-naphthaleneacetic acid (NAA) [2]. The type II Gy subunit, represented by SlGGB1, regulates ABA and auxin signal transduction in tomato [10] whereas the type III Gy subunit, represented by AGG3 in Arabidopsis, GmGr8 in soybean and DEP1 and GS3 in rice, regulates lateral root development by affecting ABA signaling, organ size and number [21]. In order to analyze whether the Gy subunit members of other Rosaceae species also have the same functional characteristics, the $G \gamma$ subunit gene expression patterns in Chinese white pear were investigated by qPCR. The results showed that Gy subunit genes exhibited diverse spatiotemporal expression patterns in various organs, with PbrGG4 being preferentially expressed in fruit, indicating that it may participate in fruit development. The expression pattern of this gene was similar to that of SlGGB1 in tomato, which was also mainly expressed in fruit, and has been implicated in the regulation of fruit morphogenesis through the auxin signaling pathway [10]. PbrGG2, PbrGG3 and PbrGG5, from Chinese white pear, exhibited preferential expression in the root, implying that these genes might function in root growth under adverse conditions through the ABA signaling pathway. In Arabidopsis, AGG1 and AGG2 were mainly expressed in the root, and mediated the osmotic stress response and root formation and growth by the auxin and ABA signaling pathways [37, 40]. PbrGG1 and PbrGG7 were mainly expressed in the ovary, indicating that they were possibly involved in flower development and sexual reproduction in plants, a finding which is consistent with previous studies by northern blot analysis that AGG3 expression was highest in reproductive tissues [19]. PbrGG3 exhibited high levels of expression in flower buds, which suggests a possible role in sexual reproduction in plants. This has not previously been reported for the G-protein subunits, and needs to be confirmed by experimentation.

Earlier studies have suggested that $\mathrm{G} \gamma$ proteins are involved in a wide range of regulation of various abiotic stress and related signaling pathways affecting growth and development at the transcript level, and have a high potential for plant improvements [25, 26, 38]. For example, Yadav et al indicated that the expression of RGG1 and RGG2 genes in rice were dramatically induced by salinity and ABA treatment [24]. In soybean, Gy subunit gene plays a key role in ABA-dependent signaling [27]. In rice, sun et al further demonstrated that the expression of Gysubunit gene (DEP1) showed different nitrogen response, and the plants carrying the dominant dep1-1 allele exhibit increase nitrogen uptake and assimilation [41]. Here, we also analyzed the expression levels of $\mathrm{G} \gamma$ subunit genes in pear by treating root and leaves with $\mathrm{N}$-deficiency or ABA. The results showed that the expression levels of $\mathrm{Gy}$ subunit genes were induced by abiotic stress, and therefor might play some specific functional in pear toward ABA-signaling pathway and nitrogen uptake and transport.

In addition, the subcellular localization analysis showed that subunits encoded by $G \gamma$ subunit genes from the three different clades, i.e., types I, II and III, were each located at the plasma membrane, with some also present in the nucleus or cytoplasm, indicating a potential capacity for $\mathrm{G} \gamma$ subunit genes to act as signal transmitters on 
the plasma membrane at the subcellular level. In other species, similar subcellular localizations of the $\mathrm{G} \gamma$ subunit proteins had been reported, with the $\mathrm{G} \gamma$ subunits playing an important role in the correct binding of the G-protein on the plasma membrane to achieve its functional specificity [37]. In Arabidopsis, the AGG3-encoded protein was located on the plasma membrane, and shown to be involved in guard cell $\mathrm{K}^{+}$-channel regulation and morphological development [19]. The protein encoded by the Gy subunit gene MGG1 was localized onto the plasma membrane, and it was suggested to act upstream of the cAMP signaling pathway, to play an important role in the regulation of conidiation, appressorium formation, mating and plant infection by the phytopathogenic fungus $M$. oryzae [31]. In rice, a series of assays confirmed the interaction of RGG1 with different stress-responsive proteins at the plasma membrane, playing crucial roles in signal transmission in response to various stresses to achieve tolerance [25].

\section{Conclusion}

In summary, $35 \mathrm{~Gy}$ subunit genes were identified and analyzed in eight Rosaceae species, with seven of these genes being from Chinese white pear. The gene structure, conserved protein motifs and phylogenetic tree analysis indicated that the $\mathrm{Gr}$ subunit genes in the eight Rosaceae species were divided into three types (I, II and III). A WGD event strongly contributed to the expansion of the Gy subunit gene family in species of the Maloideae subfamily, whereas singleton and dispersed duplication events played key roles in the expansion of the Gy subunit gene family in species of the Prunoideae and Rosoideae subfamilies. Syntenic analysis showed that purifying selection was the primary evolutionary force imposed on Gy subunit genes in the members of the Rosaceae family. Analysis of the relative expression of the seven Gy subunit genes in Chinese white pear revealed that the expression of these genes was quite extensive across a range of organs, including near-universal expression in the fruit, root, ovary, and bud, moreover, the relative expression of $P b r G G$ genes in pear root and leaf were induced by $\mathrm{N}$-deficiency stress and ABA treatment, which suggests involvement in signal delivery, directly or indirectly, in these organs. Furthermore, subcellular localization showed that most of the $G \gamma$ subunits were located on the plasma membrane, suggesting a potential capacity for $\mathrm{G} \gamma$ subunits to act as signal transmitters on plasma membranes at the subcellular level. These results provide useful information to achieve a better understanding of the evolution of the Gy subunit gene family, and to form a foundation for further studies that will investigate the structure and function of the Gy subunit gene family in the economically important plant family, the Rosaceae.

\section{Methods}

\section{Identification of Gy subunit genes in the Rosaceae}

To identify the $\mathrm{G} \gamma$ subunit genes in the Rosaceae, the Hidden Markov Model (HMM) profiles of the Gy subunit domain (PF00631.22) were downloaded from the Pfam database (http://pfam.xfam.org/). Initially, the eight genome sequences were downloaded, namely the Chinese white pear (Pyrus bretschneideri, NJAU, v1.1) genome sequence from the Pear Genome Project of the Nanjing Agricultural University (NJAU) (http://pearg enome.njau.edu.cn/), the strawberry (Fragaria vesca, GDR, v4.0), black raspberry (Rubus occidentalis, GDR, v3.0), European pear (Pyrus communis, GDR, v1.1), and sweet cherry (Prunus avium, GDR, v1.0) genome sequences from the Genome Database for the Rosaceae (GDR, http://www.Rosaceae.org/), the peach (Prunus persica, JGI, v2.1) and apple (Malus domestica, JGI, v1.1) genome sequences from the Joint Genome Institute (JGI, http://www.jgi.doe.gov/) and the Japanese apricot genome sequence from the Prunus mume (BFU v1.0) Genome Project (http://prunusmumegenome.bjfu. edu.cn/index.jsp). HMM searches were then performed against the local protein databases of the eight Rosaceae species using HMMER3 [42]. Additionally, BLAST algorithm-based searches were also performed against the eight Rosaceae genome databases, using full-length protein sequences of the identified $G \gamma$ subunit protein in Arabidopsis, and the candidate genes were selected with the e-values lower than $1 \mathrm{e}^{-100}$. A total of 58 putative $\mathrm{G \gamma}$ subunit genes were screened from the eight Rosaceae species. Furthermore, all candidate $G \gamma$ subunit genes were manually verified with the Pfam (http://pfam.xfam. org) and SMART (http://smart.embl-heidelberg.de/) domain tools to confirm the presence and completeness of the GGL domain. Those amino acid sequences lacking the GGL domain or with redundant sequences were removed.

\section{Characterization of the Gy subunit protein and phylogenetic analysis of the proteins in the Rosaceae}

To identify and analyze the conserved motifs of the proteins encoded by the $\mathrm{G} \gamma$ subunit gene family in the Rosaceae, a map of conserved motifs of all the Gy subunit amino acid sequences was carried out with the Multiple Expectation Maximization for Motif Elicitation tool (http://meme-suite.org/tools/meme; MEME version 5.0.5), with the minimum and maximum motif width being six and 200, respectively, and the number of motifs being 15. The intron/exon structures of the Gy subunit genes were determined by aligning the cDNA coding sequences with their corresponding genomic DNA sequences, which were displayed with the Gene Structure Display Server (http://gsds.cbi.pku.edu.cn/; GSDS 2.0). 
The protein isoelectric point $(\mathrm{pI})$, formula, grand average of hydropathy (GRAVY), aliphatic index and molecular weight (MW) for all eight Rosaceae species were obtained from Expasy (https://web.expasy.org/protp $\operatorname{aram} /$ ). The protein length was acquired from the corresponding genome project of each species. Each of the $\mathrm{G} \gamma$ subunit protein sequences from the eight Rosaceae species was aligned using the MUSCLE program. The phylogenetic tree was constructed and visualized using the Neighbor-Joining (NJ) method in MEGA6.0 software [43]. The parameters were set as follows: the p-distance and pairwise deletion option parameters were chosen, and the bootstrap tests was replicated 1,000 times.

\section{Chromosomal localization and syntenic analysis of the $\mathrm{G} Y$ subunit gene family}

The chromosomal locations of each of the Gy subunit genes were provided in each download from the eight Rosaceae genome annotation databases. For syntenic analysis among the eight Rosaceae genomes, a method similar to that developed for the Plant Genome Duplication Database (PGGD) (http://chibba.agtec.uga.edu/ duplication/) was conducted to determine the syntenic relationships of the Gy subunit genes. Initially, BLASTP was conducted to search for all potential inter- and intrapairwise blocks of $\mathrm{Gy}$ subunit genes among the eight Rosaceae species. Subsequently, these homologous pairs were used as the input for the MCScanX toolkit to identify collinear chains [44]. MCScanX was further used to identify whole-genome duplication (WGD), tandem, dispersed, proximal duplication and transposed duplication events in the Gy subunit gene family. Finally, the results were plotted as a circular graph using Circos software, though genes on unanchored scaffolds are not shown on the diagram [45].

\section{Calculation of $\mathrm{Ka}$, Ks and $\mathrm{Ka} / \mathrm{Ks}$ values of the $\mathrm{G} \gamma$ subunit gene family}

The values for synonymous substitutions (Ks) and nonsynonymous substitutions (Ka) were acquired from the eight Rosaceae annotation files, using the MCScanX downstream analysis tools (Calculate_Ka_Ks_pipeline), and the $\mathrm{Ka} / \mathrm{Ks}$ ratio values were calculated using these data. In brief, all inter- and intra-homologous gene pairs and the coding sequence were selected, on which were performed multiple alignments using computing_Ka Ks_pipe.pl script by MAFFT software [46]. Then, those data were converted to AXT format for submission to the KaKs_Calculator in the GMYN model [47]. Finally, the readable data were generated, including $\mathrm{Ka}$, Ks, and the $p$-value. The mean Ks was calculated by the six consecutive homologous gene pair on each side flanking the $\mathrm{G} \gamma$ subunit genes. The divergence time was calculated with the formula $\mathrm{T}=\mathrm{Ks} / 2 \mathrm{R}$, and $\mathrm{R}$ was taken to be $1.5 \times 10^{-8}$ synonymous substitutions per site per year for dicotyledonous [48].

\section{RNA extraction and qPCR assays for PbrGG genes}

To analyze the expression patterns of $\mathrm{G \gamma}$ subunit genes in Chinese white pear, total RNA was extracted independently from different pear tissues using an RNA kit (RNAsimple Total RNA Kit; Tiangen, Beijing, China), according to the manufacturer's instructions. Of the tissues used, were picked from the pear germplasm orchard of the Center of Pear Engineering Technology Research located at Hushu in Nanjing. The petal, sepal, ovary, ripening fruit and pollen grain tissue were harvested from a 6-year-old Chinese white pear tree ('Dangshan suli'), and pollen tubes were obtained from pollen grains cultured for $5 \mathrm{~h}$, whereas root, stem and leaf tissue were harvested from 2-year-old Chinese white pear seedlings ('Dangshan suli'). For the expression levels of $\mathrm{Gy}$ subunit genes in response to $\mathrm{N}$-deficiency, 5-week-old hydroponic pear seedling were transferred into the nutrient solution of $\mathrm{N}$-deficiency for five days, and samples were harvested from roots. For the expression levels of $\mathrm{G} \gamma$ subunit genes in response to ABA treatment, the leaves of 3-monthold pear seedlings were sprayed with $50 \mu \mathrm{M}$ ABA solutions, and samples were harvested from leaves at $6 \mathrm{~h}$ after treatment. Total RNA was reverse transcribed using the M-MLV reverse transcriptase (Takara Bio, Shanghai, China). The specific primers for the Gy subunit genes of Chinese white pear were designed using the Primer Premier 5.0 software [35], PbrActin was selected as the internal standard housekeeping gene and all primers are shown in Table S5. The total qPCR reaction volume was

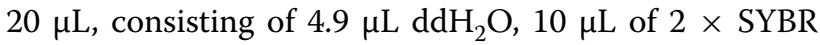
Green Master Mix, $0.1 \mu \mathrm{L}$ (100 ng) of cDNA, and $5 \mu \mathrm{L}$ $(200 \mathrm{nM})$ of the gene-specific primer mixture. The qPCR was performed using LightCycler SYBR Green I Master (Roche, USA), and the procedure was as follows: preincubation at $95^{\circ} \mathrm{C}$ for $5 \mathrm{~min}$, then 45 cycles at $95^{\circ} \mathrm{C}$ for $3 \mathrm{~s}, 60{ }^{\circ} \mathrm{C}$ for $10 \mathrm{~s}$ and $72{ }^{\circ} \mathrm{C}$ for $30 \mathrm{~s}$, and a final extension at $72{ }^{\circ} \mathrm{C}$ for $3 \mathrm{~min}$. Relative (to the internal standard) expression levels were calculated by LightCycler 480 Software v.1.5.0 (Roche, USA), using the $2^{-\Delta \Delta \mathrm{Ct}}$ method [36]. Three biological and three technical replicates were performed for each experiment, and the data were analyzed by SPSS17.0 (IBM, Armonk, NY, USA) and visualized by GraphPad Prism 8 (GraphPad Software, San Diego, CA, USA) [49].

\section{Subcellular localization assays}

The full-length coding sequence (CDS) of the Gy subunit genes PbrGG1, PbrGG4 and PbrGG6 were amplified from 
Chinese white pear root, leaf and fruit by PCR, using the corresponding primers, which are listed in Table S5. The amplified PCR products were cloned into the modified $p C A M B I A 1300-G F P$ vector carrying the CaMV 35s promoter (Clontech, Beijing, China). Subsequently, the fusion plasmids 35s::PbrGG-GFP and the control plasmid 35s:GFP were independently transferred into Agrobacterium tumefaciens cells by electroporation. Agrobacterium cells transformed with the respective fusion plasmid were then injected into tobacco (Nicotiana benthamiana) leaves, and the green fluorescence signals were visualized with a Zeiss LSM 780 Image Browser (Carl Zeiss, Inc., Thornwood, NY, USA) $3 \mathrm{~d}$ after transformation. Three independent experiments were performed for each gene.

\section{Abbreviations}

Gy subunit: Gamma subunit of heterotrimeric GTP binding protein; PGGD: Plant Genome Duplication Database; WGD: Whole-genome duplication; HMM: Hidden Markov Model; Ks: Synonymous substitutions; Ka: Non-synonymous substitutions; MEME: Multiple Expectation Maximization for Motif Elicitation; qRT-PCR: Quantitative real-time polymerase chain reaction; GFP: Green Fluorescent Protein.

\section{Supplementary Information}

The online version contains supplementary material available at https://doi. org/10.1186/s12870-021-03250-9.

Additional file 1: Table S1. Numbers of Gy subunit genes from different origins in eight Roseceae genomes

Additional file 2: Table S2. Synteny analysis of Gy subunit gene regions in Rosaceae

Additional file 3: Table S3. Ka, Ks, Ka/Ks, and divergence-time of paralogous genes among Gy subunit gene family in Rosaceae

Additional file 4: Table S4. Prediction of subcellular localization of GY subunit protein in Chinese white pear

Additional file 5. Table S5. List of primers used in this work

\section{Acknowledgements}

Not applicable.

\section{Authors' contributions}

CGD designed the research, performed the experiments, and analyzed the results. LY, QX, DWK, JC, CR and WJZ participated in carrying out the experiments. All authors have read and approved the final manuscript.

\section{Funding}

This work was supported by the Natural Science Research Project in Colleges of Jiangsu Province of China (20KJB210007).

\section{Availability of data and materials}

The data and material that support the findings of this study are available from the corresponding author on request. The pear genome datasets used during the current study are available in our pear center website (http://pearg enome.njau.edu.cn/); the strawberry, black raspberry, European pear, sweet cherry genome sequences were downloaded from the Genome Database for the Rosaceae (http://www.Rosaceae.org/); The sequence of apple and peach were downloaded from the Joint Genome Institute (http://www.jgi.doe.gov/); the Japanese apricot genome sequence were downloaded from the Prunus mume Genome Project (http://prunusmumegenome.bjfu.edu.cn/index.jsp).
The RNA-seq data were obtained from the NCBI database (https://www.ncbi. nlm.nih.gov/).

\section{Declarations}

Ethics approval and consent to participate

Not applicable.

\section{Consent for publication}

Not applicable.

\section{Competing interests}

The authors declare that they have no competing interests.

\section{Author details}

${ }^{1}$ College of Life Science and Food Engineering, Huaiyin Institute of Technology, Huai'an 223003, China. ${ }^{2}$ Center of Pear Engineering Technology Research, State Key Laboratory of Crop Genetics and Germplasm Enhancement, College of Horticulture, Nanjing Agricultural University, Nanjing 210095, China. ${ }^{3}$ Huai'an Key Laboratory for Facility Vegetables, Huaiyin Institute of Agricultural Sciences of Xuhuai Region of Jiangsu, Huai'an 223001, China.

Received: 20 May 2021 Accepted: 5 October 2021

Published online: 15 October 2021

\section{References}

1. New DC, Wong J. The evidence for G-protein-coupled receptors and heterotrimeric $\mathrm{G}$ proteins in protozoa and ancestral metazoa. Biol Signals Recept. 1998;7(2):98-108.

2. Urano D, Chen JG, Botella JR, Jones AM. Heterotrimeric G protein signalling in the plant kingdom. Open Biol. 2013;3:22.

3. Jose J, Choudhury SR. Heterotrimeric G-proteins mediated hormonal responses in plants. Cell Signal. 2020;76:109799.

4. Zhang H, Xie P, Xu X, Xie Q, Yu F. Heterotrimeric G protein signaling in plant biotic and abiotic stress response. Plant Biol. 2021;23:20-30.

5. Gautam N, Downes GB, Yan K, Kisselev O. The G-protein $\beta$ Y complex. Cell Signal. 1998;10(7):447-55.

6. Romero-Castillo RA, Choudhury SR, León-Félix J, Pandey S. Characterization of the heterotrimeric G-protein family and its transmembrane regulator from capsicum (Capsicum annuum L.). Plant Sci. 2015;234:97-109.

7. Bai L, Liu Y, Mu Y, Anwar A, He C, Yan Y, et al. Heterotrimeric G-Protein gamma subunit CsGG3.2 positively regulates the expression of CBF genes and chilling tolerance in Cucumber. Front Plant Sci. 2018;9:488.

8. Mason MG, Botella JR. Completing the heterotrimer: isolation and characterization of an Arabidopsis thaliana G protein $\gamma$-subunit cDNA. Proc Natl Acad Sci USA. 2000;97(26):14784-8.

9. McCudden CR, Hains MD, Kimple RJ, Siderovski DP, Willard FS. G-protein signaling: back to the future. Cell Mol Life Sci. 2005;62(5):551-77.

10. Subramaniam G, Trusov Y, Lopez-Encina C, Hayashi S, Batley J, Botella JR. Type $B$ heterotrimeric $G$ protein gamma-subunit regulates auxin and $A B A$ signaling in tomato. Plant Physiol. 2016;170(2):1117-34

11. Trusov Y, Chakravorty D, Botella JR. Diversity of heterotrimeric G-protein gamma subunits in plants. BMC Res Notes. 2012;5:608.

12. Choudhury SR, Bisht NC, Thompson R, Todorov O, Pandey S. Conventional and novel $\mathrm{G}$ gamma protein families constitute the heterotrimeric G-protein signaling network in soybean. PLoS One. 2011;6(8):e23361.

13. Zhang M, Tian YS, Xiao-Le HU, Ying XU, Chen F. Cloning and expression analysis of JCAGG3,G-protein gamma subunits three gene from Jatrophacurcas L. China Biotechnol. 2016;36(5):46-52.

14. Robishaw JD, Berlot $\mathrm{CH}$. Translating G protein subunit diversity into functional specificity. Curr Opin Cell Biol. 2004;16(2):206-9.

15. Pellegrino S, Zhang SY, Garritsen A, Simonds WF. The coiled-coil region of the $G$ protein beta subunit - mutational analysis of $G$ gamma and effector interactions. J Biol Chem. 1997;272(40):25360-6.

16. Trusov Y, Botella JR. New faces in plant innate immunity: heterotrimeric $G$ proteins. J Plant Biochem Biotechnol. 2012;21(1):S40-7. 
17. Wolfenstetter S, Chakravorty D, Kula R, Urano D, Trusov Y, Sheahan MB, et al. Evidence for an unusual transmembrane configuration of AGG3, a class C G gamma subunit of Arabidopsis. Plant J. 2015;81(3):388-98.

18. Kato C, Mizutani T, Tamaki H, Kumagai H, Kamiya T, Hirobe A, et al. Characterization of heterotrimeric $\mathrm{G}$ protein complexes in rice plasma membrane. Plant J. 2004;38(2):320-31.

19. Chakravorty D, Trusov Y, Zhang W, Acharya BR, Sheahan MB, McCurdy DW, et al. An atypical heterotrimeric G-protein gamma-subunit is involved in guard cell $\mathrm{K}^{+}$-channel regulation and morphological development in Arabidopsis thaliana. Plant J. 2011;67(5):840-51.

20. Jagdeep K, Swarup RC, Anitha V, Laryssa H, Zach R, Rob P, et al. Arabidopsis type III G gamma protein AGG3 is a positive regulator of yield and stress responses in the model monocot Setaria viridis. Front Plant Sci. 2018;9:109.

21. Choudhury SR, Riesselman AJ, Pandey S. Constitutive or seed-specific overexpression of Arabidopsis G-protein gamma subunit 3 (AGG3) results in increased seed and oil production and improved stress tolerance in Camelina sativa. Plant Biotechnol J. 2014;12(1):49-59.

22. Domagalska MA, Schomburg FM, Amasino RM, Vierstra RD, Nagy F, Davis SJ. Attenuation of brassinosteroid signaling enhances FLC expression and delays flowering. Development. 2007;134(15):2841-50.

23. Gao Y, Li T, Zhao Y, Ren C, Zhang Y, Wang M. Isolation and characterization of a $\mathrm{G}$ protein gamma subunit gene responsive to plant hormones and abiotic stresses in Brassica napus L. Acta Physiol Plant. 2011;33(2):391-9.

24. Yadav DK, Islam SMS, Tuteja N. Rice heterotrimeric G-protein gamma subunits (RGG1 and RGG2) are differentially regulated under abiotic stress. Plant Signal Behav. 2012;7(7):733-40.

25. Swain DM, Sahoo RK, Srivastava VK, Tripathy BC, Tuteja R, Tuteja N. Function of heterotrimeric G-protein gamma subunit RGG1 in providing salinity stress tolerance in rice by elevating detoxification of ROS. Planta. 2017; 245(2):367-83.

26. Li S, Liu Y, Zheng L, Chen L, Li N, Corke F, et al. The plant-specific G protein y subunit AGG3 influences organ size and shape in Arabidopsis thaliana. New Phytol. 2012;194(3):690-703.

27. Choudhury SR, Pandey S. Specific subunits of heterotrimeric G proteins play important roles during nodulation in soybean. Plant Physiol. 2013;162(1):522-33.

28. Zhang D, Zhang M, Zhou Y, Wang Y, Liang J. The rice G Protein gamma subunit DEP1/qPE9-1 positively regulates grain-filling process by increasing auxin and cytokinin content in rice grains. Rice. 2019;12(1):91.

29. Sun S, Wang L, Mao H, Shao L, Li X, Xiao J, et al. A G-protein pathway determines grain size in rice. Nat Commun. 2018;9(1):851.

30. Alvarez S, Choudhury SR, Sivagnanam K, Hicks LM, Pandey S. Quantitative proteomics analysis of Camelina sativa seeds overexpressing the AGG3 gene to identify the proteomic basis of increased yield and stress tolerance. J Proteome Res. 2015;14(6):2606-16.

31. Li Y, Que Y, Liu Y, Yue X, Meng X, Zhang Z, et al. The putative G gamma subunit gene MGG1 is required for conidiation, appressorium formation, mating and pathogenicity in Magnaporthe oryzae. Curr Genet. 2015;61(4):641-51.

32. Wu J, Wang ZW, Shi ZB, Zhang S, Ming R, Zhu SL, et al. The genome of the pear (Pyrus bretschneideri Rehd.). Genome Res. 2013;23(2):396-408.

33. Velasco R, Zharkikh A, Affourtit J, Dhingra A, Cestaro A, Kalyanaraman A, et al. The genome of the domesticated apple (Malus $\times$ domestica Borkh.). Nat Genet. 2010;42(10):833-9.
34. Qiao X, Li M, Li L, Yin H, Wu J, Zhang S. Genome-wide identification and comparative analysis of the heat shock transcription factor family in Chinese white pear (Pyrus bretschneideri) and five other Rosaceae species. BMC Plant Biol. 2015;15:12.

35. Chen G, Wang J, Qiao X, Jin C, Duan W, Sun X, et al. Genome-wide survey of sucrose non-fermenting 1-related protein kinase 2 in Rosaceae and expression analysis of PbrSnRK2 in response to ABA stress. BMC Genomics. 2020;21(1):781.

36. Chen G, Chen Q, Qi K, Xie Z, Yin H, Wang P, et al. Identification of Shaker $\mathrm{K}^{+}$channel family members in Rosaceae and a functional exploration of PbrKAT1. Planta. 2019;250(6):1911-25.

37. Trusov Y, Rookes JE, Tilbrook K, Chakravorty D, Mason MG, Anderson $D$, et al. Heterotrimeric $G$ protein gamma subunits provide functional selectivity in $\mathrm{G}$ beta gamma dimer signaling in Arabidopsis. Plant Cell. 2007;19(4):1235-50.

38. Botella JR. Can heterotrimeric $G$ proteins help to feed the world? Trends Plant Sci. 2012;17(10):563-8.

39. Mason MG, Botella JR. Isolation of a novel G-protein gamma-subunit from Arabidopsis thaliana and its interaction with $\mathrm{G}$ beta. BbA-Gene Struct Expr. 2001;1520(2):147-53.

40. Trusov Y, Zhang W, Assmann SM, Botella JR. G gamma 1+G gamma 2 not equal $\mathrm{G}$ beta: heterotrimeric $\mathrm{G}$ protein $\mathrm{G}$ gamma-deficient mutants do not recapitulate all phenotypes of $\mathrm{G}$ beta-deficient mutants. Plant Physiol. 2008;147(2):636-49.

41. Sun H, Qian Q, Wu K, Luo J, Wang S. Heterotrimeric G proteins regulate nitrogen-use efficiency in rice. Nat Genet. 2015;6(46):652-6.

42. Eddy SR. Accelerated profile HMM searches. PLoS Comput Biol. 2011;7(10):e1002195.

43. Tamura K, Stecher G, Peterson D, Filipski A, Kumar S. MEGA6: molecular evolutionary genetics analysis version 6.0. Mol Biol Evol. 2013;30(12):2725-9.

44. Wang YP, Tang HB, DeBarry JD, Tan X, Li JP, Wang XY, et al. MCScanX: a toolkit for detection and evolutionary analysis of gene synteny and collinearity. Nucleic Acids Res. 2012;40(7):14.

45. Krzywinski M, Schein J, Birol I, Connors J, Gascoyne R, Horsman D, et al. Circos: an information aesthetic for comparative genomics. Genome Res. 2009;19(9):1639-45.

46. Zeng W, Qiao X, Li Q, Liu C, Wu J, Yin H, et al. Genome-wide identification and comparative analysis of the $\mathrm{ADH}$ gene family in Chinese white pear (Pyrus bretschneideri) and other Rosaceae species. Genomics. 2020;112(5):3484-96

47. Wang D, Zhang Y, Zhang Z, Zhu J, Yu J. KaKs_Calculator 2.0: A toolkit incorporating gamma-series methods and sliding window strategies. Genom Proteom Bioinf. 2010;8(1):77-80.

48. Koch MA, Bernhard H, Thomas MO. Comparative evolutionary analysis of chalcone synthase and alcohol dehydrogenase loci in Arabidopsis, Arabis, and related Genera (Brassicaceae). Mol Biol Evol. 2000;17(10):1483-98.

49. Zhu X, Li Q, Tang C, Qiao X, Wu J. Comprehensive genomic analysis of the RNase T2 gene family in Rosaceae and expression analysis in Pyrus bretschneideri. Plant Syst Evol. 2020;306(4):71.

\section{Publisher's Note}

Springer Nature remains neutral with regard to jurisdictional claims in published maps and institutional affiliations. 